\title{
The Determination of the Factors Affecting Pharmaceutical Consumption in Respect to Provinces in Turkey
}

\author{
Ömer Alkan \\ Atatürk University, Department of Econometrics; Email: oalkan@atauni.edu.tr \\ Kübra Elmali \\ Atatürk University, Department of Econometrics ; Email: k.elmali@hotmail.com
}

Doi:10.5901/mjss.2015.v6n6p356

\begin{abstract}
Pharmaceutical expense constitutes a great part of health service expenses. The increase in pharmaceutical consumption will also increase the health expenses. The aim of this study is to identify the factors affecting pharmaceutical consumption of provinces with the quantile regression model based on 2013 data of Turkey. In the case of not being able to use classic regression hypothesis, quantile regression that is one of the robust regression methods has been used as an alternative to multilinear regression and analysis has been done based on various quantiles. Total pharmaceutical consumption of provinces in 2013 has been used as dependent variable. All variables in OLS and 75th quantile regression models have been found statistically meaningful. According to the results of the analysis, it has been determined that the population of the provinces consisting of 65 years old and above, life for male at birth, life for female at birth and whether the province has a coast on or no are significantly effective in pharmaceutical consumption.
\end{abstract}

Keywords: pharmaceutical consumption, OLS, quantile regression, province

\section{Introduction}

World Health Organization defines drug as "a substance or product that is prescribed to be used or being used for the purpose of examining or changing the physiological systems or pathological conditions for the benefit of the recipient". Drugs are chemical substances which have remedial effect or provide health services support for the life of human. In other words, drug is the technological product being significant for struggling with disease and preventing diseases in individual and social level (Aşıkgil, 2013; Passmore and Kailis, 1994).

Pharmaceutical expenses consist of a great of health service expenses. The increase in pharmaceutical consumption will increase the health expenses. The increase in elderly population brings about an increase in health expenses per person in the country. Aging of population is defined as the increase in the number of people who are 65 years old and above. While planning the health expenses in next years, especially expenses on pharmaceutical consumption, the elderly population should be taken into account. Indeed, health services expense per person is a function of the age. Even if the total population of a country decreases, the increase of elderly population will increase the pharmaceutical consumption (O'Neill et al., 2003; Dormont et al., 2006). Pharmaceutical consumption also differs depending on characteristical features such as sex, socioeconomic status and region of residence (Metge et al., 1999). Besides, as well as the pharmaceutical consumption in next years of a country depends on the demographical structure of the society, it also depends on the possible epidemics and the developments in health and medical technology (Van der Aa et al., 2011).

Pharmaceutical consumption per person in Turkey is very low when it is compared to developed countries (Tokgöz, 2010). However, a heavy increase has being experienced in pharmaceutical consumption recently. Whereas pharmaceutical consumption per person was 7 packages in 1989, this number increased to 16 packages in 2003. Not only pharmaceutical consumption increases in Turkey, but also inappropriate pharmaceutical consumption increases. Approximately 200 million prescriptions are written in a year in Turkey (Semin et al., 2007). There is a need to raise awareness in society of wise use of medicines, price regulations and policies to reduce the cost in order to lower the pharmaceutical consumption without decreasing the usability of medicines due to source problem especially in time of crisis (Garuoliene et al., 2011; Rüütel and Pudersell, 2011; Behmane and Innus, 2011). The rest of the study proceeds as follows. Literature research has been done related to pharmaceutical consumption and the factors affecting 
pharmaceutical consumption in section 2. Methods and data used in the study have been introduced in the section 3 . The results and comments of the estimated model have been given in the section 4. In the section 5, the discussion of the results has been done and some suggestions have been made.

\section{Literature Review}

Since medicine prices directly affect the medicine demand and pharmaceutical consumption, many countries have government policies about medicine prices. Especially in some studies, price changes of medicines in Germany (Stargardt, 2011), the effect of the changes related to medicine policies between 1995 and 2007 in Portuguese on pharmaceutical consumption (Barros and Nunes, 2010), price elasticity of medicine demands of high-income old people in Australia (Siminski, 2011), the determinants of the regulations in medicine prices and the effect of those on the demand of prescription medicine in Taiwan (Liu et al., 2012), policy changes for the pharmaceutical market after the 2008 crisis in Greece (Vandorosd and Stargardt, 2013), the effect of substitution reforms in medicine market on medicine prices in Sweden (Granlund, 2010), the applications in medicine market in the USA and the efficiency of health expenses (Hilsenrath, 2011) have been investigated. Besides, while Capri and Levaggi (2006) have dealt with price regulations in pharmaceutical expenses, Carone et al. (2012) have made an evaluation on medicine policies reducing the cost in pharmaceutical expenses of the European Union. Aşıkgil (2013) has investigated the relation between total production cost and medicine sales in 5 different pharmaceutic forms by using annual data between 2004 and 2010 with panel data regression model.

There have been studies that have been conducted by using cross-sectional data obtained by questionnaires to identify the factors affecting pharmaceutical consumption. In the recent studies, the factors affecting pharmaceutical consumption of the people staying at nursing homes in Belgium (Elseviers et al., 2010), the factors affecting pharmaceutical consumption in Spain with multinominal logistic regression (Jiménez-Rubio and Hernández-Quevedo, 2010), the waste and consumption of pharmaceutical of people in Jordan (Abushanab et al., 2013), pharmaceutical expenses and the determinants of pharmaceutical consumption of the people living in Catalonia (Costa-Font et al., 2007), the factors affecting the pharmaceutical consumption of pediatric population between 0 and 17 years-old (Clavenna et al., 2009), socio-demographic factors affecting pharmaceutical consumption in Greece (Pappa et al., 2006), financial burden of pharmaceutical consumption to people and public in Poland (Łuczak and García-Gómez, 2012) and health expenses in 1992 and 2000 in France have been examined comparatively to the data obtained by questionnaires (Dormont et al. 2006).

The factors affecting pharmaceutical consumption have been determined by using panel data and time series data on the basis of country/countries. In some studies, the factors affecting the amount of the sale of medicine prescribed by medical doctors in Iran with panel data analysis (Tahmasebi et al., 2013), the relation between health care services and pharmaceutical consumption in seven European countries (Grandfils et al., 2009), the relation between pharmaceutical consumption and life expectancy by using the data of OECD countries (Miller and French, 2000; Frech and Richard, 2004; Shaw et al., 2005; Caliskan, 2009), the reasons of increasing pharmaceutical expenses in Greece between 1991 and 2006 (Lambrelli and O'Donnell, 2011), the relation between general health results and pharmaceutical expenses in Canada (Crémieux et al., 2004) and the effect and importance of the determinants of health expenses per person (Karatzas, 2000; Fukawa and Izumida, 2004) have been examined.

There have been specific studies on pharmaceutical consumption. In the recent studies, the use of antibiotics in Scandinavian countries (Bergan, 2001), the use of orphan medicines between 2008 and 2010 in Turkey (Koçkaya et al., 2014), whether the pharmaceutical consumption has an important effect on the decrease in mortality rate related to cardiovascular in Germany (Haussler et al., 2007) have been examined. Socio-economic and demographic factors affecting the consumption of antibiotics have been investigated particularly in some studies (Nitzan et al., 2010; Filippini et al., 2009; Kern et al., 2006; Matuz et al., 2005). Evaluations on the consumption of various antibiotic medicines across the world have been done in the recent study (Van Boeckel et al., 2014).

Gallini et al. (2012) have examined the effect of medicine preferences of hospitals on pharmaceutical consumption. It has been determined that the consumption in hospitals has not positively affected the pharmaceutical consumption. Some factors such as the class and size of the hospitals have determined this effect. Van der Aa et al. (2011) have tried to estimate the effect of the increase and aging of the population in the Netherlands on pharmaceutical consumption in next years. Kisa (2006) has made a general evaluation of the medicine market and technological development in Turkey by doing a literature research. 


\section{Research Method and Data}

\subsection{Quantile Regression}

A method named quantile regression and used to estimate the functional relation between variables or between dependent variable and independent variable in any quantile value in order to eliminate the limits of classical linear regression models has been developed (Koenker ve Bassett, 1978).

Quantile regression is useful especially when conditional quantiles vary and determines the regression coefficients depending on quantiles. Whereas classical linear regression models based on the minimization of the sum of residuals' squares estimate the conditional average functions, the quantile regression models based on the minimization of the sum of cumulative absolute deviation of residuals estimate the conditional median functions and all other conditional quantile functions (Choi et al., 2012).

The basic quantile regression model is expressed as

$y_{i}=x_{i}^{\prime} \beta_{\theta}+u_{\theta i}$ with Quant ${ }_{\theta}\left(y_{i} / x_{i}\right)=x_{i} \beta_{\theta}$

$y_{i}$ is the dependent variable, $x_{i}$ is the independent variable, $\beta$ is the coefficient vector to be estimated and $u_{i}=y_{i}-x_{i} \beta$ is the residual, $\theta$. is regression quantile $(0<\theta<1)$,

$$
\begin{aligned}
& \min _{\beta} \frac{1}{n}\left\{\sum_{i: y_{i} \geq x_{j} \beta} \theta\left|y_{i}-x_{i} \beta\right|+\sum_{i y_{i} \backslash x_{i} \beta}(1-\theta)\left|y_{i}-x_{i} \beta\right|\right\} \\
& \min \frac{1}{n}\left\{\sum_{i=1}^{n} \rho_{\theta}\left(y_{i}-x_{i} \beta\right)\right\}
\end{aligned}
$$

it is estimated with minimization (Buchinsky, 1998).

The regression model is estimated as the following based on markers of $\theta$. quantile regression observation value.

$$
\theta \min _{\beta} \frac{1}{n} \sum_{i=1}^{n}\left(\theta-\frac{1}{2}+\frac{1}{2} \operatorname{sgn}\left(y_{i}-x_{i}^{\prime} \beta\right)\left(y_{i}-x_{i}^{\prime} \beta\right)\right)
$$

Here, $\operatorname{sgn}(\alpha)$ is the marker of $\alpha$ and if $\alpha$ is positive, it takes 1 and if it is negative or 0 , it takes 1 value (Koenker ve Bassett, 1978).

\subsection{Data}

The data of pharmaceutical consumption (the number of pillbox) according to provinces in 2013 in Turkey has been obtained from Turkish office of IMS Health company. IMS Health is a company providing the support of information, data, service and technology for health sector. It also provides extensive data support to the researchers if they want. The data related to independent variables included in the model has been obtained from the website of Turkish Statistical Institute. Independent variables are the population of 65 year-olds and above of the provinces, life expectancy at birth for men and women in respect to provinces and the condition whether the province has a coast on or not.

\section{Results}

\subsection{Descriptive Statistics}

The definitions of dependent and independent variables in this study are shown in Table 1.

Table 1. Definitions of variables.

\begin{tabular}{ll}
\hline Variables & Definition \\
\hline CONSUMPTION & The number of pillbox consumed in the province \\
AGE65 & The number of people aged 65 and above \\
LiFE_FOR_MALE & Life expectancy of males in the province at birth \\
LIFE_FOR_FEMALE & Life expectancy of females in the province at birth \\
SEA & Whether the province has a coast on or not \\
\hline
\end{tabular}

The VIF technique was used to test the existence of multicollinearity. The VIF values for all variables are below 5 , and 
thus no multicollinearity was detected. The descriptive statistics of the variables used in this study are shown in Table 2. In 2013, the number of pillbox which consumed for the provinces is average 21959720.79. Pharmaceutical consumption data distribution of provinces is positive skew and leptokurtic.

Table 2. Descriptive statistics of the model variables $(\mathrm{N}=81)$

\begin{tabular}{lccccccc}
\hline Variable & Mean & Median & Max & Min & Std. Dev. & Skewness & Kurtosis \\
\hline Dependent variable & & & & & & & \\
CONSUMPTION & 21959720.79 & 10800411 & 360853934 & 1012097 & 43544879.74 & 6.31 & 46.97 \\
LnCONSUMPTION & 16.24 & 16.20 & 19.70 & 13.83 & 1.06 & 0.42 & 0.68 \\
Independent variables & & & & & & & \\
AGE65 & 72736.96 & 45554.00 & 828811.00 & 7651.00 & 106652.25 & 5.13 & 32.66 \\
LiFE_FOR_MALE & 73.58 & 73.70 & 76.30 & 70.20 & 1.39 & -0.37 & -0.28 \\
LIFE_FOR_FEMALE & 79.04 & 79.20 & 82.20 & 74.00 & 1.51 & -0.65 & 0.80 \\
SEA & 0.33 & 0.00 & 1.00 & 0.00 & 0.47 & 0.72 & -1.52 \\
\hline
\end{tabular}

To better explain our findings, we provided the pharmaceutical consumption distribution in Table 3. For example, the pharmaceutical consumption at the 25 th percentile was 5593535,5 , indicating that 20 percent of the provinces have a pharmaceutical consumption lower than 5593535,5.

Table 3. Percentiles and Pharmaceutical Consumption $(\mathrm{N}=81)$

\begin{tabular}{ccc}
\hline Percentile & CONSUMPTION & InCONSUMPTION \\
\hline 5 & 2228953,6 & 14,62 \\
10 & 3209272,6 & 14,98 \\
15 & 4017697,0 & 15,21 \\
20 & 4594158,6 & 15,34 \\
25 & 5593535,5 & 15,54 \\
30 & 6795552,6 & 15,73 \\
35 & 7302379,8 & 15,80 \\
40 & 8139598,4 & 15,91 \\
45 & 9353190,3 & 16,05 \\
50 & 10800411,0 & 16,20 \\
55 & 11782706,2 & 16,28 \\
60 & 12636264,4 & 16,35 \\
65 & 14853159,2 & 16,51 \\
70 & 19786548,6 & 16,80 \\
75 & 22725472,0 & 16,94 \\
80 & 27606675,4 & 17,13 \\
85 & 35569620,8 & 17,38 \\
90 & 42486426,8 & 17,56 \\
95 & 61701051,8 & 17,94 \\
\hline
\end{tabular}

\subsection{Model Estimation}

The following equation is the basic model of the empirical study:

InCONSUPMTION $i=a+\beta_{1}$ AGE65i $+\beta_{2}$ LIFE_FOR_MALE $i_{i}+\beta_{3}$ LIFE_FOR_FEMALE $i_{i}+\beta_{4} D_{i} S E A_{i}+u_{i}$

where $i=1, \ldots, N$ ( $N$ being the number of observations). $D i S E A i$ which is a dummy variable identifying whether the province has a coast on or not ( If the coast province $D=1$ or $D=0$ ).

The results of OLS and quantile regression have been demonstrated in Table 4. All variables in OLS regression model have been found statistically meaningful. While the variables of Age65, Life for male and Sea have positive effect on pharmaceutical consumption, the variable of Life for female has negative effect. When the models of quantile regression have been examined, the effect of the population aged 65 and over in the provinces is positive on pharmaceutical consumption and it has been found statistically meaningful in all quantile regression models. The effect of coefficient has risen in especially high quantiles. Life expectance of male at birth has been found meaningful in 75th quantile regression and it has positive effect on pharmaceutical consumption. Life expectancy of female at birth has been found meaningful in 10th, 50th and 75th quantile regression models and it has negative effect on pharmaceutical 
consumption. Whether the province has a coast on or not has been found statistically meaningful in 50th and 75 th quantile regression models. It can be said that pharmaceutical consumption of the province increases because the province has a coast on. Consequently, it has been seen that the results of models in high quantiles are better.

Table 4. Results of OLS and the quantile regression model.

\begin{tabular}{|c|c|c|c|c|c|c|}
\hline & \multirow{2}{*}{ OLS } & \multicolumn{5}{|c|}{ Quantile Regression Models } \\
\hline & & $q=0,10$ & $q=0,25$ & $q=50$ & $q=75$ & $q=90$ \\
\hline CONSTANT & $\begin{array}{c}240947^{\star} \\
(4.635) \\
\end{array}$ & $\begin{array}{l}27.843^{*} \\
(10.193)\end{array}$ & $\begin{array}{c}20.732^{\star *} \\
(8.333)\end{array}$ & $\begin{array}{l}22.122^{*} \\
(4.337)\end{array}$ & $\begin{array}{l}26.077^{*} \\
(4.248)\end{array}$ & $\begin{array}{l}30.261^{*} \\
(10.420) \\
\end{array}$ \\
\hline AGE65 & $\begin{array}{l}6.35 \mathrm{e}-06^{\star *} \\
(7.85 \mathrm{e}-07)\end{array}$ & $\begin{array}{l}5.31 \mathrm{e}-06^{*} \\
(1.14 \mathrm{e}-06)\end{array}$ & $\begin{array}{l}8.04 \mathrm{e}-06^{*} \\
(2.17 \mathrm{e}-06)\end{array}$ & $\begin{array}{l}8.84 \mathrm{e}-06^{*} \\
(7.17 \mathrm{e}-07)\end{array}$ & $\begin{array}{c}0.00001^{*} \\
(5.05 \mathrm{e}-07)\end{array}$ & $\begin{array}{c}0.00001^{*} \\
(1.21 \mathrm{e}-06)\end{array}$ \\
\hline LiFE_FOR_MALE & $\begin{array}{l}0.260^{*} \\
(0.109) \\
\end{array}$ & $\begin{array}{c}0.383 \\
(0.268)\end{array}$ & $\begin{array}{c}0.205 \\
(0.229)\end{array}$ & $\begin{array}{c}0.207 \\
(0.105)\end{array}$ & $\begin{array}{l}0.184^{\star \star} \\
(0.086)\end{array}$ & $\begin{array}{c}0.122 \\
(0.178)\end{array}$ \\
\hline LIFE_FOR_FEMALE & $\begin{array}{l}-0.349^{*} \\
(0.104)\end{array}$ & $\begin{array}{c}-0.524^{\star *} \\
(0.249)\end{array}$ & $\begin{array}{l}-0.261 \\
(0.206)\end{array}$ & $\begin{array}{l}-0.276^{*} \\
(0.097)\end{array}$ & $\begin{array}{l}-0.302^{*} \\
(0.086)\end{array}$ & $\begin{array}{l}-0.292 \\
(0.176)\end{array}$ \\
\hline SEA & $\begin{array}{c}0.538^{\star} \\
(0.190)\end{array}$ & $\begin{array}{c}0.840 \\
(0.528)\end{array}$ & $\begin{array}{c}0.395 \\
(0.338)\end{array}$ & $\begin{array}{c}0.522^{*} \\
(0.180)\end{array}$ & $\begin{array}{l}0.398^{\star \star} \\
(0.186)\end{array}$ & $\begin{array}{c}0.096 \\
(0.489)\end{array}$ \\
\hline $\begin{array}{l}\mathrm{R}^{2} \\
\text { Pseudo } \mathrm{R}^{2}\end{array}$ & $\begin{array}{c}0.58 \\
-\end{array}$ & 0.2789 & 0.2815 & 0.3799 & $\begin{array}{c}- \\
0.4635\end{array}$ & 0.4741 \\
\hline
\end{tabular}

Note: ${ }^{*}<0.01 ;{ }^{*} p<0.05$; Standard errors are reported in the parentheses

Figure 1 indicate coefficient estimates of OLS and quantile regression models. The vertical axis represents the estimated parameter for each exogenous variable, whereas the horizontal axis displays the quantile. The horizontal lines plot the OLS estimate and its $95 \%$ confidence interval.
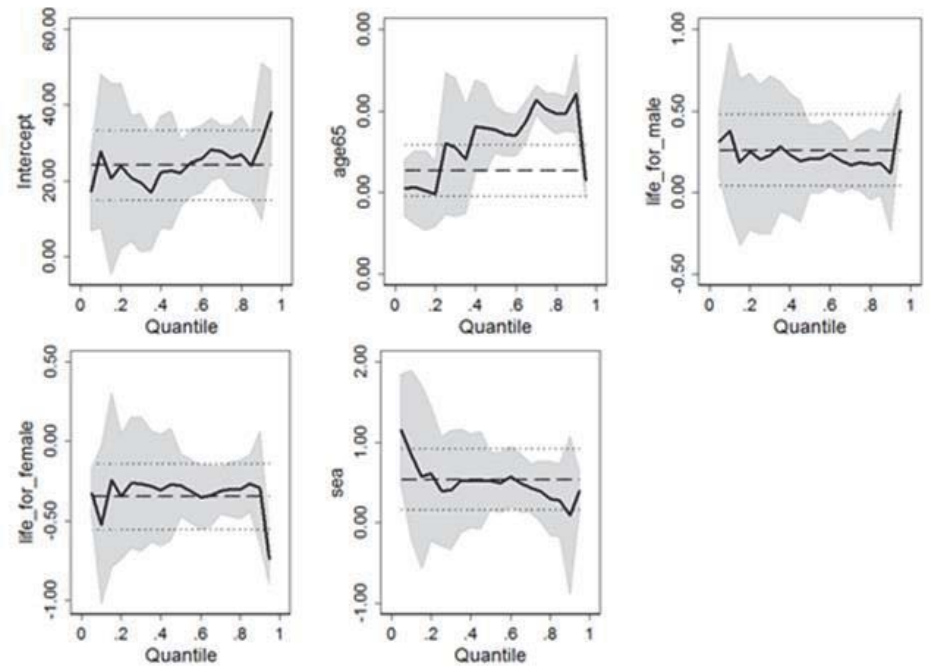

Figure 1. Coefficient estimates of OLS and quantile regressions.

\section{Discussion}

Medicines have become an indispensable element of human life. Due to the recently growing and aging population in Turkey, pharmaceutical consumption and accordingly pharmaceutical expenses have been increasing. The aim of this study is to identify the factors affecting pharmaceutical consumption at province level for 2013. The variables such as population structure of provinces, location, and life expectancy can be effective in pharmaceutical consumption. According to the results, it has been determined that pharmaceutical consumption rises as the population aged 65 and 
above of the provinces increases. Considering the studies in the literature, it has been identified that increase in elderly population increases the pharmaceutical consumption (Dormont et al., 2006; Van der Aa et al. 2011; Pappa et al., 2006; Karatzas, 2000). However, when Elseviers et al. (2010) has examined the factors affecting pharmaceutical consumption of the people staying at nursing homes in Belgium, he cannot find a linear relation between age and pharmaceutical consumption. It has been observed that pharmaceutical consumption decreases after the age of 70 . Similarly, Fukawa and Izumida (2004) have stated that health expenses per person start to decrease after the age group of 85-89.

In the recent studies, it has been found out that variables such as gender (Costa-Font et al., 2007; Tahmasebi et al. 2013; Jiménez-Rubio and Hernández-Quevedo, 2010), age (Clavenna et al., 2009; Tahmasebi et al., 2013; JiménezRubio and Hernández-Quevedo, 2010), the level of income (Costa-Font et al., 2007; Abushanab et al., 2013), region (Clavenna et al., 2009), the state of disease (Costa-Font et al., 2007), private health insurance (Jiménez-Rubio and Hernández-Quevedo, 2010), the use of cigarettes and alcohol (Jiménez-Rubio and Hernández-Quevedo, 2010) and the behavior of doctors (Lambrelli and O'Donnell, 2011) have positive effect on pharmaceutical consumption. It has been determined in some studies that there is a positive relation between life expectancy and pharmaceutical consumption (Grandfils et al., 2009; Miller and French, 2000; Shaw et al., 2005; Frech and Richard, 2004; Caliskan, 2009). Life expectancies of male and female at birth have been taken as separate variables in this study. Whereas positive relation has been found between life expectancy of males at birth and pharmaceutical consumption, a negative relation has been found in females.

Clavenna et al. (2009) have identified in the study related to pharmaceutical consumption of children whose ages range between 0 and 17 that the region of the children influences pharmaceutical consumption. The condition of the province as to whether it has a coast on or not affects the pharmaceutical consumption positively in the quantile regression models of OLS, 50th and 75th in this study.

This study has some limitations. The study has been conducted only with the data of 2013 and according to 81 provinces in Turkey. More comprehensive results could have been obtained if the data at county level had been reached. In further studies, pharmaceutical consumptions of provinces can be investigated with panel quantile regression model by considering the data of previous years. Training activities based on especially visual and auditory materials should be extended by policy makers in order to raise awareness of conscious pharmaceutical consumption of people. The levels of pharmaceutical consumption should be tried to estimate by conducting studies about changes in population structure in the future.

\section{References}

Abushanab, A.S., Sweileh, W.M., \& Wazaify, M. (2013). Storage and wastage of drug products in Jordanian households: a crosssectional survey, International Journal of Pharmacy Practice, 21(3), 185-191.

Aşıgil, B. (2013). Analyzing the consumption of various pharmaceuticals in Turkey: a panel approach, Turkiye Klinikleri Journal of Biostatistics, 5(2), 55-60.

Barros, P. P., \& Nunes, L. C. (2010). The impact of pharmaceutical policy measures: an endogenous structural-break approach, Social Science \& Medicine, 71, 440-450.

Behmane, D., \& Innus, J. (2011). Pharmaceutical policy and the effects of the economic crisis: Latvia, Eurohealth, 17(1), 8-10.

Bergan, T. (2001). Antibiotic usage in Nordic countries", International Journal of Antimicrobial Agents, 18, 279-282.

Buchinsky, M. (1998). Recent advances in quantile regression models: a practical guideline for empirical research, The Journal of Human Resources, 33(1), 90-101.

Caliskan, Z. (2009). The relationship between pharmaceutical expenditure and life expectancy: evidence from 21 OECD countries, Applied Economics Letters, 16, 1651-1655.

Capri, S., \& Levaggi, R. (2006). International price regulations in the pharmaceutical sector: a common model to sharing the benefits, Journal of Pharmaceutical Finance, Economics and Policy, 15(2), 21-30.

Carone, G., Schwierz, C., \& Xavier, A (2012). Cost-containment policies in public pharmaceutical spending in the EU. Economic Papers 461, Belgium: European Commission.

Choi, D., Hoffman, K.A., Kim, M.O., \& McCarty, D. (2012). A high-resolution analysis of process improvement: use of quantile regression for wait time, Health Services Research, 48(1), 333-347.

Clavenna, A., Sequi, M., Bortolotti, A., Merlino, L., Fortino, I., \& Bonati, M. (2009). Determinants of the drug utilization profile in the paediatric population in Italy's Lombardy Region, British Journal of Clinical Pharmacology, 67, 565-571.

Costa-Font, J., Kanavos, P., \& Rovira, J. (2007). Determinants of out-of-pocket pharmaceutical expenditure and access to drugs in Catalonia, Applied Economics, 39, 541-551.

Crémieux P.-Y., Mieilleur, M.-C., Ouellette, P., Petiti P., Zelder, P., \& Potvin, K. (2005). Public and private pharmaceutical spending as determinants of health outcomes in Canada, Health Economics, 14, 107-116.

Dormont, B., Grignon, M., \& Huber, H. (2006). Health expenditure growth: reassessing the threat of ageing, Health Economics, 15, 947963. 
Frech, H. E., \& Richard, D. M. (2004). The effects of pharmaceutical consumption and obesity on the quality of life in the organization of economic cooperation and development OECD countries, PharmacoEconomics, 22, 25-36.

Fukawa, T., \& Izumida, N. (2004). Japanese healthcare expenditures in a comparative context, The Japanese Journal of Social Security Policy, 3(2), 51-61.

Elseviers, M.M., Vander Stichele, R. R., \& Van Bortel, L. (2010). Drug utilization in Belgian nursing homes: impact of residents' and institutional characteristics, Pharmacoepidemiology and Drug Safety, 190, 1041-1048.

Filippini, M., Masiero, G., \& Moschetti, K. (2009). Small area variations and welfare loss in the use of outpatient antibiotics, Health Economics, Policy and Law, 4, 55-77.

Gallini, A., Legal, R., \& Taboulet, F. (2012). The influence of drug use in university hospitals on the pharmaceutical consumption in their surrounding communities, British Journal of Clinical Pharmacology, 75(4), 1142-1148.

Garuoliene, K., Alonderis, T., \& Marcinkevicius, M. (2011). Pharmaceutical policy and the effects of the economic crisis: Lithuania, EuroHealth, 17, 1-4.

Grandfils, N., Hauser, S., Amalric, F., \& Le Pen, C. (2009). Does pharmaceutical consumption improve health care status?, Value in Health, 12(7), A239.

Granlund, D., (2010). Price and welfare effects of a pharmaceutical substitution reform, Journal of Health Economics, 29 (6), $856-865$.

Haussler, B., Schiffhorst, G., Gothe, H., \& Elke H. (2007). The impact of pharmaceuticals on the decline of cardiovascular mortality in Germany, Pharmacoepidemiology and Drug Safety, 16, 1167-1176.

Hilsenrath, P. (2011). Health expenditure efficiency: implications for pharmaceutical marketing, International Journal of Pharmaceutical and Healthcare Marketing, 5(2), 118 - 134

Jiménez-Rubio, D., \& Hernández-Quevedo, C. (2010). Explaining the demand for pharmaceuticals in Spain: are there differences in drug consumption between foreigners and the Spanish population?, Health Policy, 97, 217-224.

Karatzas, G. (2000). On the determination of the us aggregate health care expenditure, Applied Economics, 32, 1085-1099.

Kern, W. V., de With, K., Nink, K., Steib-Bauert, M., \& Schröder, H. (2006). Regional variation in outpatient antibiotic prescribing in Germany, Infection, 34, 269-73.

Kisa, A. (2006). Analysis of the pharmaceuticals market and its technological development in Turkey, International Journal of Technology Assessment in Health Care, 22(4), 537-542.

Koçkaya, G., Wertheimer, A. I., Kilic, P., Tanyeri, P., Vural, İ. M., Akbulat, A., Artiran, G., \& Kerman, S. (2014). An overview of the orphan medicines market in Turkey", Value in Health Regional Issues, 4, 47-52.

Koenker, R., \& Bassett G. (1978). Regression quantiles, The Econometric Society, 46(1), 33-50.

Lambrelli, D., \& O'Donnell, O. (2011). The impotence of price controls: failed attempts to constrain pharmaceutical expenditures in Greece, Health Policy, 101, 162-171.

Liu, Y.-M., Yang, Y.-H. K., \& Hsieh, C.-R. (2012). Regulation and competition in the Taiwanese pharmaceutical market under national health insurance, Journal of Health Economics, 31, 471-483.

Łuczak, J., \& García-Gómez, P. (2012). Financial burden of drug expenditures in Poland, Health Policy, 105, $256-264$.

Matuz, M., Benko, R., Doro, P., Haidu, E., Nagy, G., Nagy, E., Monnet, D. L., \& Soos, G. (2005). Regional variations in community consumption of antibiotics in Hungary, 1996-2003, British Journal of Clinical Pharmacology, 61, 96-100.

Metge, C., Black, C., Peterson, S., \& Kozyrskyj, A.L. (1999). The population's use of pharmaceuticals, Managed Care, 37(6), 42-59.

Miller, Jr R.D., \& French H.E., (2000). Is there a link between pharmaceutical consumption and improved health in OECD countries?, Pharmacoeconomics, 18, 33-45

Nitzan, O., Low, M., Lavi, I., Hammerman, A., Klang, S., \& Raz, R. (2010). Variability in outpatient antimicrobial consumption in Israel, Infection, 38, 12-18.

O’Neill, D. C., Hughes, C. M., Jamison, J., \& Schweizer, A. (2003). Cost of pharmacological care of the elderly, Drugs \& Aging, 20(4), 253-261.

Pappa, E., Kontodimopoulos, N., Papadopoulos, A. A., Tountas, Y., \& Niakas, D. (2006). Determinants of pharmaceutical consumption in a general population, Value in Health, 11(6), A366-A367.

Passmore, P.R., \& Kailis, S.G. (1994). In pursuit of rational drug use and effective drug management: clinical and public health pharmacy viewpoint, Asia Pac J Public Health, 17(4), 236-241.

Rüütel. D., \& Pudersell. K. (2011). Pharmaceutical policy and the effects of the economic Crisis: Estonia, Eurohealth, 17(1), 5-8.

Shaw, J. W., Horrace, W. C., \& Vogel, R. J. (2005). The determinants of life expectancy: an analysis of the OECD health data, Southern Economic Journal, 71 (4), 768-783.

Semin, S., Aras, S., \& Guldal, D. (2007). Direct-to-consumer advertising of pharmaceuticals: developed countries experiences and Turkey, Health Expect, 10, 4-15.

Siminski, P. (2011), The price elasticity of demand for pharmaceuticals amongst high-income older Australians: a natural experiment, Applied Economics, 43, 4835-4846.

Stargardt, T. (2011). Modelling pharmaceutical price changes in Germany: a function of competition and regulation, Applied Economics, $43,4515-4526$.

Tahmasebi, N., Zadeh, A. K., Imani, A., \& Golestani, M. (2013). Evaluation of factors affecting sales of prescription medicines by econometric methods in Iran, Pharmaceutical Sciences, 19(3), 101-107.

Tokgöz, T. (2010). The Turkish pharmaceutical market, Journal of Generic Medicines: The Business Journal for the Generic Medicines Sector, 7 (3), 270-274. 
Van Boeckel, T.P., Gandra, S., Ashok, A., Caudron, Q., Grenfell, B. T., Levin, S. A., \& Laxminarayan, R. (2014), Global antibiotic consumption 2000 to 2010: an analysis of national pharmaceutical sales data, Lancet Infect Dis, 14, 742-750

Van der Aa, N.G.F.M, Kommer, G.J, Van Montfoort J.E., \& Versteegh, J.F.M. (2011). Demographic projections of future pharmaceutical consumption in the netherlands, Water Science and Technology, 63(4), 825-831.

Vandoros, S., \& Stargardt, T. (2013). Reforms in the Greek pharmaceutical market during the financial crisis, Health Policy, 109, 1-6. 